\title{
Travestilidades no espaço socioeducativo: (des)patologização, monstruosidade, violência, abjeção e negação das identidades transgêneras
}

\author{
Travestilidades in the socioeducative space: (des) patologization, monstruosity, \\ violence, abjection and refusal of transgener identities
}

Jonas Alves da Silva Junior

Doutor em Educação pela Universidade de São Paulo, e docente do Programa de PósGraduação em Educação (PPGEDUC) e da graduação da Universidade Federal Rural do Rio de Janeiro. Rio de Janeiro, RJ, Brasil. jonasjr@usp.br

Maria de Lourdes Silva

Doutora em Filosofia e Ciências de Educação pela Universidade Complutense de Madri. Professora Livre-docente da Faculdade de Educação da Universidade de São Paulo. São Paulo, SP,

Brasil. mlramos@usp.br

Leandro Rodrigues Nascimento da Silva Graduando do curso de Letras pela Universidade Federal Rural do Rio de Janeiro. Rio de Janeiro, RJ, Brasil. leandrosalesufrrj@outlook.com

\begin{abstract}
Resumo: Este ensaio pretende tecer uma reflexão sobre as identidades trans no espaço socioeducativo. Tendo como base uma pesquisa empírica, realizada em uma unidade masculina de privação de liberdade do Departamento Geral de Ações Socioeducativas (DEGASE/RJ), e tendo como aporte teórico autores/as dos Estudos Culturais/pós-estruturalistas, busca-se compreender de que maneira pessoas travestis ou transexuais circulam em espaços cuja homo/transfobia é difundida ao grau máximo. Assim, a partir da metáfora do corpo monstro/abjeto, analisamos como a socioeducação opera no sentido de não desbaratar os engessamentos de gênero e os estereótipos de masculinidade vigentes entre os adolescentes acautelados. Como resultado deste trabalho, sinaliza-se que práticas discursivas referendadas pela cisheteronormatividade determinam ao sujeito uma única forma de construção da masculinidade, que são explícita e implicitamente impostas. A presença (ou pressuposição) de sujeitos não-cisheterossexuais em instituições de privação de liberdade impulsiona subjetividades normativas reproduzidas por práticas de intolerância, medo e violências.
\end{abstract}

Palavras-chave: Identidades trans. Travesti. Gênero. Socioeducação. Privação de liberdade

Abstract: This essay aims at reflecting on trans identities in the socio-educational space. Based on an empirical
research carried out in a male deprivation of liberty unit of the General Department of Socio-educational
Actions (DEGASE/RJ), and with the theoretical contribution of the Cultural/Post-structuralist Studies, it is
sought to understand that travestis or transsexual people circulate in spaces whose homo/transphobia is
diffused to the maximum degree. Thus, from the metaphor of the monster/abject body, we analyze how the
socioeducation operates in the sense of not disrupting the gender engagements and the stereotypes of masculinity among precarious adolescents. As a result of this work, it is pointed out that discursive practices endorsed by the cisheteronormativity determine 
to the subject a unique form of construction of the masculinity, that is explicitly and implicitly imposed. The presence (or presupposition) of non-hetero-sexual subjects in institutions of deprivation of liberty propels normative subjectivities reproduced by practices of intolerance, fear and violence.

Keywords: Trans identities. Transvestite. Gender. Socioeducation. Deprivation of liberty

\section{Introdução}

Com desvelo, este artigo objetiva aquilatar o funcionamento de uma unidade do Departamento Geral de Ações Socioeducativas (Degase) do município do Rio de Janeiro. Também objetiva dissecar as propostas que são oferecidas pela unidade, no que tange ao acolhimento das identidades transgêneras, ao seu legítimo reconhecimento enquanto parte intrínseca, subjetiva, polissêmica e indissociável do ser humano e o combate à LGBTfobia. Nos debruçamos sobre as práticas pedagógicas e o espaço escolar, pois é sabido que a educação, ao longo dos séculos, serviu como um instrumento regulador, coercitivo, disciplinador, o qual auferiu poder a discursos de classes hegemônicas e patriarcais engendrando relações de dominação social, cultural e de gênero.

Ela também dividiu, internamente, os que lá estavam, através de múltiplos mecanismos de classificação, ordenamento, hierarquização. A escola que nos foi legada pela sociedade ocidental moderna começou por separar adultos de crianças, católicos e protestantes. Ela também se fez diferente para os ricos e para os pobres e ela imediatamente separou os meninos das meninas (LOURO, 2010, p. 57).

Assim, a prática pedagógica pode ser concebida como uma verdadeira ferramenta estratégica. O Degase encontra-se com uma gama de dificuldades acerca do convívio de travestis e transexuais com os adolescentes que se intitulam heterossexuais. Dificuldades que, prementemente, necessitam de serem debeladas, visando prospectivamente o bem-estar, a segurança e a garantia das identidades de gênero das jovens trans; identidades essas que são taxativamente asseguradas por legislação específica e órgãos de proteção aos direitos das crianças e dos/as adolescentes.

O Degase, em parceria com a secretaria de Estado de Educação, é a instituição incumbida de administrar as medidas socioeducativas, que serão aplicadas às crianças e aos adolescentes, prescritas por um juiz/a competente. A instituição deve executar as medidas balizada pelos parâmetros evocados no Estatuto da Criança e do Adolescente (ECA), Lei n ${ }^{\circ}$ 8.069/1990 e em coadunação e aquiescência com o que está definido no Sistema Nacional de Atendimento Socioeducativo (SINASE), Lei nº 12.594.

O SINASE é um documento imprescindível para o funcionamento das unidades socioeducativas e, além de reafirmar o que reza o ECA, ele se imbrica com os compromissos 
acordados internacionalmente no campo dos Direitos Humanos dos quais o Brasil é signatário. Compromissos esses que afiançam o direito à identidade de gênero (GONÇALVES, 2014). Mas, afinal, quem são as travestis/transexuais? Quem são esses sujeitos que reivindicam uma identidade que é tornada abjeta nas unidades de privação de liberdade? Na socioeducação, quem ocupa o lugar de “monstro”? (PELÚCIO, 2009) E qual seria o território destinado para as identidades trans conviverem humanamente e serem legitimamente reconhecidas na esfera socioeducativa?

\section{Sobre o universo trans}

Para que fique mais aclarado sobre o nosso sujeito de estudo, é preciso conceituá-lo. Para isso, contamos com o apoio de Peres, que conceituou os sujeitos trans como

[...] pessoas que se constituem através de processos de subjetivação que oscilam entre discursos e figurações normatizadoras que tentam disciplinar seus corpos e regular seus prazeres, inaugurando um novo campo por meio de movimentos de resistência e de enfrentamento ao biopoder. (PERES, 1999, p. 540).

Assim, surge o que categorizamos como sujeitos travestis/transexuais. Pessoas que inauguram uma nova estética filosófica e corporal, que claudicam na cisheteronormatividade arvorando-se contra os moldes sociais binarista e falocêntrico viril (BENTO, 2017). É um agente humano que resiste às lógicas universalizantes e à inteligibilidade do que é ser homem e do que é ser mulher, espraiando a sua legítima e inventiva forma de 'existencialização'.

Apesar de sujeitos constituídos a partir de expressões de múltiplos devires, e com isso constatarmos que não são, portanto, sujeitos unos, eles fazem das travestilidades uma crítica singular; uma crítica realizada com o próprio corpo, o qual se nega a ser um sujeito assujeitado aos padrões normativos da sexualidade, que tentam deixar impressos em seus corpos, filosofia e sentimentos a marca da regulação binarista homem/mulher. É por meio de uma performance, uma prática repetitiva de ações demandadas pela subjetividade, que nada tem a ver com a interioridade individual estrutural biológica, que um sujeito encontra a liberdade idealizada corporificando a idealização de uma identidade, paulatinamente construída por diversas intervenções fraturadas, e tornando-se um/a jogador/a no trânsito dos discursos regulatórios.

As práticas de encenação de um gênero são recíprocas, podendo ou não serem bem concebidas pelos demais sujeitos circundantes, e nos diversos contextos em que se manifesta (BUTLER, 2003). As identidades transgêneras assumem um papel preponderante no que tange ao enfrentamento ao biopoder, sendo, portanto, o exemplo mais proeminente da 
subversão, do engendramento, da resistência e das novas possibilidades criadas, em contrapartida, pela força repressora binarista. Como argumentaria o pensamento foucaultiano (FOUCAULT, 1987), que traz uma contribuição importante para os Estudos Culturais e os Estudos Feministas, com um insight instigador o qual se baseia na percepção do poder não só como algo destrutivo, improdutivo ou um percalço intransponível; mas compreendendo-o também como força motriz que de forma invisível cria e faz-se positivo e produtor.

Como corolário desse poder regulador dos corpos em constante processo e trânsito, podemos considerar que onde há discursos persecutórios instituidores de poder, há também um grande potencial de transgressão. O poder então pode ser concebido como um dispositivo utilizado em direções diferentes, e por diferentes indivíduos, sendo interpretado como estratégias de enfrentamento, "[...] manobras, as táticas, as técnicas, os funcionamentos.” (FOUCAULT, 1987, p. 35). As identidades de gênero e sexuais estão articuladas, imbricadas e adictas, desbaratando as normas dos gêneros, que se balizam num ponto de vista androcêntrico ao qual se nutre do arquétipo da figura identitária masculina como a única possibilidade biológica capaz de permanência de existência e significação. Nessa linha, todas as outras identidades seriam constituídas a partir da identidade masculina hegemônica.

A proposta das identidades transgêneras é desconstruir o gênero pretensamente universal, para torná-lo mais plural e harmônico (LAURETIS, 1994). A forma de inteligibilidade que o Ocidente gestou de pensamento acerca dos gêneros sempre presume a fulcral dicotomia masculino/feminino, lançando para fora de sua órbita todo aquele indivíduo que não se enquadre nesse modelo. Esse formato engessado binarista é duramente criticado por muitos/as estudiosos/as feministas. Eles/as veem esse engendramento como originário do pensamento de pesquisadores/as da academia, de classe média e de cor branca.

Os sujeitos trans apresentam-se como uma proposta marcadamente sedutora e fértil de renovação de pensamento e quebra desse sistema dicotomizado. Pois eles revelam que um contém o outro, que o masculino e o feminino fazem parte de uma intersecção social e subjetiva, cujas bases de formação possuem implicações externas globais (ou de outros modelos sociais que diferem na interpretação dos gêneros daquela forma cultural a qual o sujeito encontra-se inserido). Acerca desse pensamento, Hall afiança que:

Nenhuma identidade singular - por exemplo, de classe social - podia alinhar todas as diferentes identidades com uma "identidade mestra", única, abrangente, na qual se pudesse, de forma segura, basear uma política. As pessoas não identificam mais seus interesses sociais exclusivamente em termos de classe; a classe não pode 
servir como um dispositivo discursivo ou uma categoria mobilizadora através da qual todos os variados interesses e todas as variadas identidades da pessoa possam ser reconciliadas e representadas. De forma crescente, as paisagens políticas do mundo moderno são fraturadas por identificações rivais e deslocantes - advindas, especialmente, da erosão da "identidade mestra" da classe e da emergência de novas identidades, pertencentes à nova base política devida pelos novos movimentos sociais. (HALL, 1992, p. 81).

Nesse sentido, discursos beligerantes surgirão, contendo um poder inconspícuo no seu significado, porém fortalecido no próprio significante emitido, o qual presumirá, diante das identidades transgêneras, o não-reconhecimento ou a perda da sua legítima prática de exercício social e sexual heteronormativo. Parece-nos que as relações entre pessoas do mesmo gênero são interpretadas como uma ameaça em potencial da instituição histórica humana. Relações que são interpretadas como dignas de morra per ello. No entanto, devem ser interpretadas como um indicativo cabal que proporciona um vislumbre mais nítido de novas estilísticas sexuais.

No bojo da unidade socioeducativa pesquisada, há uma série de emulações que irrompem acerca das masculinidades que devem ser encenadas. Apesar de os adolescentes, antes do acautelamento, fazerem parte de uma comunidade de prática de masculinidade, no microcosmo socioeducativo, eles se inserem numa subsociedade de prática de masculinidades (PAECHTER, 2009). Essas "subsociedades" são grupos menores que repensam sobre o que é ser homem e o que é ser mulher. Para eles, a masculinidade não diz respeito àquilo que os homens fazem cotidianamente, e como exibem os seus corpos, embora faça parte do processo. Mas, generalizando-se para as demais formas, é a maneira perceptiva como eu (self) penso que sou a partir de uma baliza concebida pelo coletivo, o qual me dita como devo ser através da disciplina dos corpos (JORGE e TRAVASSOS, 2018).

O que o self encena faz parte do processo regulatório que se inicia no corpo, posteriormente no pensamento abstrato, e, novamente, consumando-se no corpo. A regulação dos corpos apresenta uma fronteira, alocando as travestilidades/transexualidades numa categoria de 'monstro'. Os indivíduos trans precisam, por isso, serem separados dos demais alunos. Eles são postos em um espaço chamado "Seguro" ou "Protetora" a fim de que não padeçam violências física, verbal e psicológica. A categoria de inteligibilidade 'monstro' carrega simbolismos fortes. Para Cohen (2000, p. 27) o vocábulo possui sua origem na língua latina monstrum que se traduziria como "aquele que algo revela, que faz severas advertências".

Butler (2003, p. 161) nos dá subsídios epistemológicos para melhor esclarecimento do ato de nomear e categorizar as coisas ao nosso redor. A pesquisadora presume que "a 
nomeação é, ao mesmo tempo, o estabelecimento de uma fronteira e também a inculcação repetida de uma norma”. A categoria monstro atina para um viés desprezado e circunscrito, fadado a limites, zonas longínquas, rincões onde só haja parelhas de igual condição. Pesa também o fato de nas histórias infantis, os monstros morarem sempre em ilhas isoladas por águas profundas, lugares escuros, cavernas impenetráveis e limites não-humanos.

Na perspectiva sexual, o monstro revelaria as práticas mais sórdidas, impróprias e fora da lei. Práticas sexuais que só devem ser realizadas por parte do corpo do próprio monstro (TURCHERMAN, 1999). Porém, também é possível constatar que essa categoria rivaliza, no que tange à concepção das identidades transgêneras por parte dos socieducandos, com a categoria 'doente sexual'. Uma influência conceptiva do século XIX, quando surgem as ciências sexuais e a patologização das identidades sexuais por meio do discurso científico pretensamente universal, que grassou no cenário social contribuindo para formas sedentárias de pensamento.

Ademais, se calcarmos os pés nos meandros da história, veremos que as nossas ciências sexuais surgiram com a inteligibilidade sobre os binômios "saúde/doença, lei/crime (LEITE JUNIOR, 2012, p. 566). Assim, se no século XIX as identidades sexuais desviantes do padrão heteronormativo foram taxadas como crime, no século XX seriam consideradas doenças, desvios ou transtornos sexuais e de gênero. Tendo, novamente no século XXI, um fantasma que reincide em alocá-las no bojo das doenças.

Em particular, o sistema socioeducativo não se mostra capaz de receber e garantir o direito dos sujeitos transgêneros. No decurso de nossa pesquisa, entrevistamos funcionários/as de áreas diversas que atuam na unidade socioeducativa masculina, e lidam diretamente com os adolescentes. Muitos/as dos/as quais debateram acerca da falta de preparo profissional para lidarem com a pluralidade sexual que permeia a instituição.

Ao todo, tivemos como interlocutores 5 (cinco) profissionais que atuam na área da Educação, dentre eles, 2 (duas) professoras; 2 (dois) da área psicossocial; e 3 (três) agentes da segurança. Além dos/as socioeducadores/as, entrevistamos também 10 (dez) adolescentes acautelados na unidade em que a pesquisa foi realizada. Seguimos todos os protocolos éticos exigidos pelo Degase e pelas diretrizes da pesquisa em Ciências Humanas. Dessa forma, todos/as os/as interlocutores/as assinaram termo de autorização para pesquisa, assim como houve autorização judicial para que os/as adolescentes pudessem ser entrevistados. Ademais, em hipótese alguma a unidade será identificada. Tal providência vale também para os/as interlocutores/as e demais sujeitos aqui mencionados, que terão suas 
respectivas identidades preservadas. O que veremos a seguir, então, é parte do resultado do "mergulho" que fizemos na unidade socioeducativa de privação de liberdade masculina entre os meses de maio e setembro de 2018.

\section{Identidades trans na socioeducação}

A maioria dos/as profissionais nunca teve um curso de formação voltado para questões que orbitassem a temática dos/as GBTsii . Os/as profissionais se deram conta do despreparo quando se defrontaram com um embaraçoso imbróglio engendrado pela chegada de uma aluna travesti na unidade.

A presença daquele corpo híbrido, bem harmonizado em suas possibilidades causou nos profissionais uma reflexão retrospectiva, à medida em que o passado não lhes havia auferido conhecimentos para lidarem com aquele fato, e prospectiva, pois teriam de repensar as suas normas e discursos. Neste ponto vale ressaltar também a falta de apoio do Estado, e o tratamento dado às identidades transgêneras como identidades abjetas. Abjetas não numa classificação adjetiva, como trivialmente tem sido usado, com o sentido de algo repulsivo, execrável, vil, fomentador de horror. Todavia, numa semântica idiossincrática em que devemos concebê-la como "[...] o que, na constituição do sujeito socialmente inteligível, é colocado 'de fora' desse sujeito, tornando-se seu exterior constitutivo" (LEITE JUNIOR, 2012, p. 560).

Não obstante, o abjeto é o que se encontra excluído das concepções do pensamento social sedentário. A identidade abjeta é não categorizável; valendo salientar que as nomeações linguísticas são também categorias do pensamento abstrato que se coadunam com as alteridades humanas (LEITE JUNIOR, 2011). Assim, o abjeto fica de fora das possibilidades de "existencialização" coletiva, pois estaria além das inteligibilidades religiosas, jurídicas, culturais e hegemônicas nas quais se estabelece as comunidades com forte viés binarista. Nesta concepção, a sua legitimidade como partícipe de uma das subsociedades de prática de masculinidade e feminidade torna-se contingente, frívola e instável para com os demais participantes.

A aluna travesti, segundo relato dos/as socioeducadores/as ouvidos/as, causou um mal-estar tão grande na unidade socioeducativa masculina que foi enviada para uma unidade socioeducativa feminina. Chegando nesta unidade, também não foi bem-aceita. $O$ fato da adolescente se vestir como uma mulher, não mitigava, para o alunado feminino, a "ameaça" do falo o qual ela possuía. Com acusações descabidas subterfugiadas por um argumento 
biológico sugestivamente taxativo, as adolescentes exerciam a identificação do gênero como uma supervalorização dos atributos corporais da aluna travesti, neste caso, o pênis.

Nessa unidade, havia casais lésbicos, e a adolescente que assumia a identidade social e sexual masculina, via na adolescente travesti uma ameaça, pois "ela tinha pênis" e isso poderia comprometer gravemente o seu relacionamento amoroso. Se na unidade socioeducativa masculina o pênis simbolizava um certo privilégio natural, um instrumento que conferia ao portador certo "poder", capaz de preencher vaginas, e não só preenchê-las, mas também preencher as entranhas femininas durante nove meses, na unidade feminina ele simbolizava um poder muito pior e muito mais devastador: o da marca fronteiriça dos gêneros.

Nesta perspectiva, o gênero não é concebido como uma leitura, uma interpretação elaborativa culturalmente instituída do sexo biológico, mas, este é interpretado como sendo o próprio gênero pelas alunas. Neste ponto, aquelas subsociedades de prática de masculinidade e de feminidade convergiam na inteligibilidade de que o sexo biológico determina os demais tipos de identidades (social, gênero e sexual).

O caso da aluna travesti não teve também solução na unidade feminina, tendo os/as diretores/as da unidade que realocá-la na unidade masculina. A recondução da aluna à unidade de primeiro acesso foi necessária pela grande quantidade de pais e mães que, irrequietos/as e não conformados/as, debateram pedindo que ela fosse transferida. Diante do revés indelével, e das posturas agressivas não só da comunidade extraescolar, mas também dos/as próprios/as agentes socioeducativos/as, foi preciso transferi-la.

A sua estadia na unidade de primeiro ingresso não foi a das mais convencionais. A aluna ficava sempre sozinha numa cela, sendo aceita somente por professores/as e profissionais da unidade. Tempos depois, os adolescentes que haviam cometido crime de estupro eram colocados juntos com ela no mesmo exíguo lugar. Trazendo para esta questão uma problematização e uma criticidade mais acurada: será que de maneira diáfana equiparava-se a identidade transgênera a uma identidade patológica criminosa pulverizada no contexto do crime?

O entendimento das identidades sexuais como desviantes da norma cisheteronormativa e reduzidas à identidades abjetas se dá mediante um movimento pendular histórico e processual, no qual ora os indivíduos trans são concebidos como "monstros" impudicos, dissolutos, energúmenos, que precisam de um banimento simbólico ou literal, ora na categoria abjeta a fim de que sejam banidos/as de vez da órbita inteligível social. 
Essa categoria seria a última forma e a mais cruel de todas, pois, se algo se torna inconcebível, intangível e não compreendido, este algo se pulveriza, ganhando um manto de uma não existência. E o que não existe não possui direitos, respeito, seguridade, cidadania e dignidade, a qual toda a pessoa humana precisa ter. A chegada da aluna travesti na unidade revelou a sua não inclusão nas possibilidades de pensamento do Estado, da família e da religião. Para aquela aluna, simplesmente não havia política de acolhimento, de segurança e de recuperação e inserção social.

Esse fato engendrou novos desafios para os profissionais daquela instituição, desestabilizou certezas, condutas e procedimentos que costumeiramente eram adotados por eles para com as crianças e os adolescentes, pois eles precisaram montar um verdadeiro plano pedagógico para conseguir alocar a nova aluna com os demais; direcioná-la para um alojamento onde não fosse agredida pelos demais, inseri-la nos momentos básicos de interação humana, como atividades ao ar-livre, refeições etc; e um desafio principal: reconhecer que estavam diante de uma identidade transgênera e que precisavam respeitá-la.

Mas os esforços realizados pelos agentes socioeducativos, somatizados aos esforços dos/as professores/as e de toda a equipe pedagógica não foram suficientes para assegurarem à adolescente um direito instituído por lei. As agressões vinham por vias linguísticas, ameaças de morte com a "Teresa" iii, ameaças de estupro coletivo e espancamento. Tempos mais tarde, os adolescentes estabeleceram uma norma, que deveria ser cumprida dentro dos alojamentos, que seria a não citação do nome da aluna travesti, numa amostragem de aniquilamento total daquela identidade, a qual passava de "monstro" para uma abjeção.

Essa afirmação se corporifica na fala de um adolescente, em um dos vários colóquios que realizamos, quando ele diz: "Ele (o indivíduo desviante da circunscrição heteronormativa) não poderia [...] ver os outros tomando banho. Nem conversar. Tinha que ficar isolado". Butler (2010, p.158) nos sinaliza para o fato de que, por sermos indivíduos linguísticos, a fala é um ato corporal, o qual intensificando-se no momento em que se fala, damos existência ao que se diz.

Os adolescentes arquitetaram essa norma da não citação da aluna travesti, e a garantiram por meio do olhar onipresente regulador. Se um deles falasse o nome do "monstro", um outro colega de alojamento logo o delataria, expondo-o ao grupo, o qual caberia decidir a punição ao transgressor da norma. O processo de inculcação da norma agride, marca o psicológico dos adolescentes de tal forma que mesmo sem ter ninguém por perto que possa delatá-los para o seu grupo em caso de eventual transgressão de alguma 
regra, eles se mantêm calados, optando pelo silêncio que grita, mas mantendo o acordado e rechaçando o verberado.

Foi o que aconteceu em uma de nossas entrevistas com os socioeducandos. Passamos um vídeo para instigar a discussão sobre o abuso sexual dentro daquela unidade. Aspirávamos por saber se eles tinham algum relato acerca do que perguntávamos. $\mathrm{Na}$ sala de entrevista, estava eu e mais dois/duas pesquisadores/as. Eles (os alunos) assistiram ao vídeo calados: de quando em quando riam-se de alguma cena; mas, quando questionados acerca do assunto que estava sendo abordado no vídeo, optaram por respostas monossilábicas ou simplesmente sinalizavam com a cabeça.

Um dos adolescentes rebelou-se numa amostragem clara da não aceitação de ideias dissidentes da sua ou de ter protagonizado uma cena de abuso sexual, na qual poderia ter sido vítima ou agressor. Saiu da sala de forma repentina, e não mais retornou. Transcorridos alguns minutos daquele colóquio, o qual exigia diálogo dos/as pesquisadores/as e dos adolescentes, percebemos que ali havia uma esfera de vigilância panóptica (FOUCAULT, 1987).

Segundo Foucault (1987), com base nas ideias do filósofo e jurista Jeremy Bentham, o termo "panoptismo" é utilizado para categorizar uma espécie de prisão que seria perfeita e a vigilância dos presos um sucesso. A sua construção seria em forma circular, cujo centro se elevaria uma grande torre; alta o bastante que impedisse os prisioneiros de avistarem quem estava em cima dela. $\mathrm{O}$ vigilante, que teria visão privilegiada de tudo, poderia ou não estar no alto da torre, que os prisioneiros, com receio de que estivessem sendo vigiados e passíveis de severas punições, se comportariam da maneira que lhes fora ditada.

O mesmo observou-se entre os adolescentes. Quando tomamos ciência de tudo através da observação atenta, resolvemos entrevistá-los separadamente, e os alunos se sentiram um pouco mais à vontade para relatarem os casos de abuso sexual e homo/transfobia que perpassam os alojamentos da instituição. Mesmo assim, de quando em quando eles trocavam olhares entre si, numa lembrança de que a vigilância permanecia presente, mesmo distante do que era audível.

Porém, a estratégia surtiu bons resultados. 56\% dos alunos entrevistados disseram ter presenciado episódios de preconceito contra homossexuais e pessoas trans. Episódios esses enredados por impropérios, depreciação das identidades transgêneras, tornando-as combalidas em sua legitimidade, tornando-as sinônimos de alcunhas pejorativas e, por fim, áridas para o coletivo. Metade dos socioeducandos pesquisados possuem excertos de abuso 
sexual para contar; excertos de casos que ocorreram na unidade pesquisada. Esta que conta com vinte e seis professores/as, dentre os/as quais apenas dois/duas abordam a questão da sexualidade com os adolescentes. No entanto, somente um/a trabalha com frequência essas questões. Mesmo assim, sempre voltadas para vertentes que não tratam da LGBTfobiaiv. Como resultado da inoperância com essa temática, 67\% dos socieducandos revelaram não saber o que significa a palavra "homofobia".

Esquadrinhando o interesse dos alunos pela temática da sexualidade, constatamos que $41 \%$ deles consideravam o ensino da educação sexual importante. $27 \%$ consideravam desnecessário e 32\% não souberam responder. Com total diligência, é possível presumir que o interesse por parte dos socioeducandos na temática da sexualidade aumenta extraordinariamente. Só lhes falta o aporte curricular a fim de somatizar forças no combate à homo/transfobia.

Quando falamos do currículo na socioeducação, de certa maneira estamos tratando não só de uma lista de conteúdos a serem trabalhados com as crianças e os adolescentes, mas estamos nos referindo a todo o mobiliário da unidade, aos corpos que circulam ali e nas suas reclamações. Tudo isso constitui a relação curricular que, por si só, já nos revela uma abertura propensa à diversidade cultural, religiosa e de gênero. Partindo dessa premissa, os conteúdos propriamente ditos, a serem ministrados nas aulas, os materiais didáticos e paradidáticos devem contemplar essa diversidade.

A prerrogativa de estabelecer entre os conteúdos os temas transversais da educação que compõem o currículo escolar é dos professores/as. Todo o início de ano letivo, os/as profissionais se reúnem para decidirem o que deverão levar para a sala de aula. Comumente isso também é realizado noutras instituições de ensino. Não obstante, essas instituições seguem um currículo bem mais engessado com metas e datas. Quanto ao currículo da socioeducação, observamos que os/as professores/as recebem da Secretaria de Educação sugestões, que podem ou não entrar nos programas a serem trabalhados com as crianças e os adolescentes. Sendo assim, a questão de gênero pode ser trabalhada pelos/as profissionais com tranquilidade. Todavia, não é o que se observa.

Num esquadrinhamento do material utilizado pelos/as professores/as com os alunos, visitamos uma sala onde ficam guardados DVDs; dos quais não faltam filmes de ação, comédia e violência. Os DVDs ultrapassavam um total de cem discos. Também sistematizamos algumas estantes de livros, os quais certamente ultrapassavam o número de duzentos volumes. Contudo, mesmo com essa quantidade considerável de material didático 
e paradidático, não encontramos nada que versasse sobre a temática de gênero, LGBTfobia e diversidade sexual. Dessa maneira, as identidades trans não vislumbram ações eficazes capazes de mitigar o preconceito sofrido nas esferas da socioeducação. Irrompem no cenário de privação de liberdade como mais um entre tantos; não obstante, um sujeito não existente, o qual passa pelo sistema como um percalço, um objeto que necessita de ser evitado. Se os esforços para combater as violências sexuais são poucos, o mobiliário e suas condições de acautelamento apresentam-se com um imenso esforço em promovê-las.

A unidade pesquisada encontra-se com um número de alunos muito maior do que pode comportar. A capacidade de acolhimento dos discentes era de 203 vagas. Contudo, a unidade estava com 243 discentes. Nas celas, as camas são de solteiro, pequenas e para dois alunos dormirem. A forma menos sofrível encontrada pelos socioeducandos foi a de dormirem de costas um para o outro. Soubemos de um relato, que nos foi contado por uma coordenadora pedagógica, o qual nos chamou bastante atenção. Um adolescente foi violentado sexualmente por outro no período de um mês.

Todas as noites a violência se reverberava liturgicamente. Passados alguns dias, a professora notou que o adolescente violentado se mantinha sempre muito compenetrado nas aulas. A profissional notou que aquela ausência participativa reclamava atenção especial. Com muita diligência, a professora começou um diálogo com o adolescente no intuito de saber o que se passava com ele. Depois de muitas delongas discursivas, a profissional conseguiu fazer com que o aluno falasse algo. Ele revelou a ela que era obrigado a fazer sexo com o outro companheiro de alojamento todas as noites. O agressor dizia que se a vítima o delatasse, decerto seria morta com a "Teresa".

\section{Considerações finais}

O conhecimento corporal aparece aqui como um marcador de autoridade e poderio, em que o maior e mais forte gesta uma relação de poder para com os demais inferiores corporalmente (BOURDIEU, 2005). Sendo assim, as trans saem extremamente prejudicadas, pois são vistas como homens franzinos, vestidos de mulher e por isso mesmo destituídos de poder ou crédito social. Ao mesmo tempo em que se nega que o aluno trans seja uma mulher, pelo crivo ideológico sexista, machista e misógino, atribui-se ao socioeducando trans uma fraqueza advinda das encenações femininas. Isso gera um processo, no qual é quase impossível ao aluno trans se defender dos demais. 
As relações entre os sujeitos pressupõem encontros culturais, encontros de formações discursivas várias, capazes de se autolegitimarem como dotadas de poder natural. Quando sugerimos que seja feita uma nova formulação curricular capaz de abranger a diversidade sexual e as questões de gênero, estamos sugerindo a criticidade da realidade opressora, que a comunidade GBT sofre todos os dias nas unidades de privação de liberdade, a fim de que essa opressão real seja denunciada pelos diversos meios de construção do conhecimento. Isso resultará numa nova pedagogia a qual liberta e não só se presta ao acúmulo de conhecimento. Como defende o patrono da educação brasileira, Paulo Freire, é preciso transformar o indivíduo em sujeito de sua própria história (FREIRE, 1996).

É preciso transformar as identidades transgêneras em identidades socialmente reconhecidas e conscientes de sua própria existência legítima. As incorporações de ações no currículo que objetivem esse fim requerem também certa politização por parte dos/as profissionais da educação, os quais precisam zelar e priorizar uma educação libertadora que difere da sectária e dogmática. Sendo assim, anunciando nos currículos da socieducação uma nova realidade na qual todos/as são agentes humanos repartindo de um ideal comum, que seria a garantia de direitos e a justiça para todos e todas.

\section{Referências}

BENTO, Berenice. Transviad@s: gênero, sexualidade e direitos humanos. Salvador: Edufba, 2017.

BOURDIEU, Pierre. Dominação Masculina. $4^{\circ} \mathrm{ed}$. Rio de Janeiro: Bertrand Brasil, 2005.

BRASIL. Lei Federal, de 05 de outubro de 1988. Constituição da República Federativa do Brasil. Brasília, 1988. Disponível em:

<http://www.planalto.gov.br/ccivil_03/Constituicao/ConstituicaoCompilado.htm. Acesso em: 18 de jan. 2019.

BRASIL. Estatuto da criança e do adolescente: Lei Federal nº 8069, de 13 de julho de 1990. Rio de Janeiro: Imprensa Oficial, 2002.

BRASIL. Sistema Nacional de Atendimento Socioeducativo - SINASE/ Secretaria Especial de Direitos Humanos - Brasília - DF: CONANDA: 2006.

BUTLER, Judith. Problemas de gênero: feminismo e subversão da identidade. Rio de Janeiro: Civilização Brasileira, 2003.

BUTLER, Judith. "Corpos que pensam: sobre os limites discursivos do 'sexo". In: LOURO, Guacira Lopes (Org.). O corpo educado: pedagogias da sexualidade. Belo Horizonte: Autêntica, 2010, p. 151-172.

COHEN, Jeffrey Jerome. A cultura dos monstros: sete teses. In: SILVA, Tomaz Tadeu da (Org.). Pedagogia dos monstros. Belo Horizonte: Autêntica. 2000, p. 23-60. 
DECLARAÇÃO UNIVERSAL DOS DIREITOS HUMANOS. Assembleia Geral das Nações Unidas em Paris. 10 dez. 1948. Disponível em:

<htpp://www.dudh.org.br/wpcontent/uploads/2014/12dudh.pdf>. Acesso em: 20 jan. 2019.

FOUCAULT, M. Vigiar e punir. $7^{\circ}$. ed. Petrópolis: Vozes, 1987.

FREIRE, Paulo. Pedagogia da autonomia. Rio de Janeiro: Paz e Terra, 1996.

GONÇALVES, Camila de J.M. Transexualidade e Direitos Humanos: o reconhecimento da identidade de gênero entre os direitos da personalidade. Curitiba: Juruá, 2014.

HALL, S. "A questão da identidade cultural”. In: HALL, S.; HELD, D \& McGREW, T. (Orgs.) Modernity and its futures. Cambridge: Polity/ Open University, 1992.

JORGE, Marco Antonio C.; TRAVASSOS, Natalia P. Transexualidade: o corpo entre o sujeito e a ciência. Rio de Janeiro: Zahar, 2018.

LEITE JUNIOR, J. “Transitar para onde? Monstruosidade, (des)patologização, (in)segurança social e identidades transgêneras”. Estudos feministas, Florianópolis, v. 20, n 2, p. 559-568, ago., 2012.

LEITE JUNIOR, J. Nossos corpos também mudam: a invenção das categorias "travesti” e transexual" no discurso científico. São Paulo: Annablume, 2011.

LOURO, Guacira Lopes. Gênero, sexualidade e educação: uma perspectiva pós-estruturalista. 11‥ ed. Petrópolis, RJ: Vozes, 2010.

LAURETIS, T. “A tecnologia do gênero”. In: HOLLANDA, H. (Org.). Tendências e impasses: o feminismo como crítica da modernidade. Rio de Janeiro: Rocco, 1994.

PELÚCIO, Larissa. Abjeção e desejo. São Paulo: Annablume, 2009.

PAECHTER, Carrie F. Meninos e meninas: aprendendo sobre masculinidades e feminidades. Tradução, consultoria e supervisão Rita Terezinha Schmidt. Porto Alegre: Artmed, 2009.

PERES, Wiliam Siqueira. "Travestilidades nômades: a explosão dos binarismos e a emergência queering”. Estudos feministas, Florianópolis, v. 20, nº 2, p. 539-549, ago., 2012.

TUCHERMAN, Leda. Breve história do corpo e de seus monstros. Lisboa: Veja, 1999.

\section{Notas}

\footnotetext{
2 Morra per ello: expressão de raízes castelhanas, trivialmente utilizada no antigo Código Criminal das Ordenações Filipinas, que regiam o direito luso-brasileiro. A expressão equivale à imperativa: seja condenado/a à morte.

3 Por se tratar de uma unidade a qual só recebe o público do gênero masculino, removemos da sigla (LGBT) a letra "L", que representa as lésbicas. Lendo-se, portanto, Gays, Bissexuais, Travestis, transexuais, transgêneros (GBTs).

${ }^{4}$ Pedaço de pano úmido utilizado para matar por asfixia. O pano é enrolado no rosto da vítima. Enquanto um dos agressores o aperta forte, um outro agressor segura os braços da pessoa agredida.
} 
${ }^{5}$ Medo, aversão, repulsa, nojo, ideais filosóficos que azeitem as relações de ódio contra as lésbicas, gays, bissexuais, travestis, transexuais, transgêneros etc.

Recebido em: 15 abr. 2019 / Aprovado em: 25 jun. 2019

\section{$\underline{\text { Cite como }}$}

SILVA JUNIOR, Jonas Alves da; SILVA, Maria de Lourdes; SILVA, Leandro Rodrigues Nascimento da. Travestilidades no espaço socioeducativo: (des)patologização, monstruosidade, violência, abjeção e negação das identidades transgêneras. Dialogia, São Paulo, n. 32, p. 93-107, maio/ago. 2019. Disponível em: https://doi.org/10.5585/Dialogia.n32.13641. 